\title{
Action Research and Model Innovation in Backbone Teachers Training for Science Course
}

\author{
Yufei $\mathrm{Wu}^{1}$ \\ ${ }^{1}$ Chemical and material science college, \\ Hebei Normal University, \\ ShiJiaZhuang City, P.R.China
}

\author{
Zhongqiang Zhang ${ }^{2}$ \\ ${ }^{2}$ Department of Applied Chemistry, \\ HengShui University, \\ HengShui City, P.R.China
}

\begin{abstract}
The model for backbone teacher training for science course (BTTSC) at the provincial level has innovated and built in this paper. It depends on the traditional training model being analyzed, the Action Research Theory (ART) as the instruction, and the content of science exploration for primary and secondary school backbone teacher training practice. So it will provide reference for further raise the effectiveness of BTTSC.
\end{abstract}

Keywords-action research theory; scientific backbone teacher; training model; innovation

\section{INTRODUCTION}

On the job training for science teacher continuing education is an important part of basic education course reform. To research the advanced theory and successful experience on teacher training at home and abroad plays an important role to accelerate the construction of professional science course teachers and improve the ability of science course teacher's effective implementation of new curriculum. Since 2006, 8 batches of provincial BTTSC for primary and secondary school have token on by the science education specialized subject of Hebei Normal University. The domestic and foreign advanced training mode has paid attention to in the training, and the pattern of primary and secondary schools for BTTSC has been explored and innovated, too.

\section{The Problems Existing In The TRAditional TRAINING AND TRAINING INNOVATION TASK BEING PUT FORWARD}

Teacher training model refers to the gradually formed in the teacher training practice and built about teachers' training system or structure under the guidance of the theory of activity method and procedure in a certain teacher training ${ }^{[1]}$.

Admittedly, in the process of the BTTSC curriculum reform of primary and secondary school itself is an exploratory activity. From BTTSC requirements, BTTSC will be lacked necessary reference curriculum system and training pattern when a branch of normal colleges and universities was applied indiscriminately in the past training ${ }^{[2]}$. In addition, the training content falls less pertinence, the training model is monotonous, and so on.

There are a few defects in such training. Firstly, the idea of training education is serious lag, such as simply put trained teachers on was the location of the trainees, ignored the self-reflection, independent construction of teachers, and the reaction of the trainees in the training. Secondly, the extensionality of the training work was ignored. Quite a number work of training was only paid attention to the achievements of training at certain stage, and ignoring backbone teachers for science course (BTSC) to pursue long-term development source of demand. A stark contrast has been showed between backward traditional training model and science curriculum reform idea and demand. Therefore, fledgling BTTSC model being bold innovated will play a crucial role in the construction of science course teachers.

\section{ESTABLISH A BTTSC MODEL By INNOVATION ART}

ART is defined in international education Encyclopedia as: the reflective study was implemented in order to improve rational knowledge of the society or education practice, to deepen the understanding of the practice and its dependence on the background by the participants of social scene or education situation.

In fact, ART is an education research activities and not an independent research method. It is a kind of education research activities that the purpose is to promote the improvement of education work directly through teachers and education management combined with their work and comprehensive use of various effective methods ${ }^{[3]}$. So the characteristic function and value of ART provides a new angle of view to think BTTSC model. It has important theoretical and practical significance to improve the quality of BTTSC.

\section{A. Equality participation of researcher, trainer, and trainee is} as the premise of BTTSC model innovation

John elliott (the representative figure of ART thinks: education idea, the education thought, education theory is not the patent of researchers of education theory, and the new growing point of education theory can not be produced if teachers education life without actual experience. So, BTTSC mode must be based on cooperation of scientific theoretical researchers, trainers and trainee. In training, the training concept and method should be to discuss, evaluate, reconstruct in BTTSC; Theory researchers should help trainers to form the research mode so as to contribute to teaching work through dialogue and consultation,

\section{B. TTSC mode should be as a constantly construct the dynamic process of development}

ART emphasizes that the teacher should constantly bring new ideas, knowledge, information, values integration into the existing "subjective theory" through reflection and practice. As a dynamic and open system, Science course itself is not only to 
the basic knowledge of science, the research methods and ways of thinking together, but also realize to reconstruct the existing "subjective theory" through the science knowledge from the books being associated with the science of social life. So, the BTTSC mode should be dynamic and open, too. The specific demands of science curriculum and specific functions and value orientation for the provincial BTTSC determine the training work that should be timely dynamic adjustment according to actual condition

\section{Relocate relationship between subject and object in BTTSC}

The researchers of ART believe the method that learners gain understanding and knowledge of things meaningful is actively to construct on the basis of their experience but not pass on knowledge [1]. So, the trainees are not passive recipients of knowledge, but actively construct knowledge. That is, the trainees should be the real subject of the training activities. The essence of ART is to liberate the 'trainees' of traditional research ${ }^{[4]}$. So the trainees should realize themselves research and bring value construction to trainees through the practice, communication, discussion, and other learning activities in training. The value construction to trainees is not only to improve them cognitive ways and skills, but also to grasp the method and enhance their ability.

\section{Organize training around facing practical problems of BTSC}

The practice activity is the only source of research content for ART. The practical problems encountered in science course should be focused on in training. As common problems, the living examples should be analysis and the cases should be guided besides the theoretical study. The trainees should reflect them based on the analysis of the relevant education behavior, and find and solve problems through reflection. The ability on education practice for trainees should be promoted in improving their teaching behavior in the process of education.

\section{EXPLORE INNOVATIVE BTTSC MODEL}

The most basic elements of training model include training subject, training objects, training objectives, training content, training methods, training management, etc ${ }^{[5]}$. So the exploration for innovative BTTSC is as follows:

\section{A. The relationship for subject and object between the trainers and trainees should be rebuilt with research theme from beginning to end.}

The main training subjects of BTTSC generally refer to the teachers of training colleges, the external employment experts and the training managers of training institutions. At present, the training objects mainly refer to BTSC that are selected to attend the training from the elementary or middle school. In fact, BTSC are in the stage of a balanced development of teaching and research ability, higher ability of self-reflection, consciously to self-planning, and the desire of seeking maximum development. The idea of trainees as main subjects is in the process from the design of the training scheme, modality of course content, and the arrangement of the training activities, and trainers as the masters to participate in the training.
The thesis should be the breakthrough point that the trainers always guide the trainees, and the trainees can successfully carry out all assigned tasks under the guidance of the trainers in the whole training process. The traditional relationship of the subject and object has implemented to rebuild in the process training, research, retrieval of literature, and visit.

\section{B. Emphasize to aim at trainees' humanistic features on the training goal and the content}

"Student centered" is the aim of the school work. The trainees are not just hired as a teacher, and not teaching experts. The purposes of BTTSC are to improve their abilities of working effectively, overcoming difficulties, and accomplish task through training. In summary, the training objectives of BTTSC are to as much as possible to carry out specific results that BTSC implement new curriculum, to improve effectively their attitude, knowledge and skills in the face of the new curriculum.

1) Attitude training: The "scientific nature and its value in science and education" special speech has been reported by a science education expert in Beijing normal university to make trainees realize the difference in the science course with the natural science course and the general branch of science curriculum. The actualities have changed only to pay attention to science knowledge. The relatively whole contemporary science curriculum system has built by associating the target property of scientific knowledge with property of science process.

2) Knowledge training: The university physics, chemistry, life science, geographical science, astronomy academic leaders have been hired as the trainers of BTTSC based on advantage of college science professional discipline. The experts made a series of professional lecture that the topics were "basic and frontier", respectively. By guiding to visit a few the national key laboratories and provincial key laboratories, the trainers make the trainees not only from the knowledge but the perspective of research to understand the science, comprehend cause and effect of science, and to realize the dynamic development of science.

3) Ability training: Many questions in teaching have no fixed answers and a large amount of specific work without reference model because the teaching characteristics of science course are the exploration and open. How to implement the reform and how to improve the development has become very urgent problem in the science curriculum reform. The weakness of the primary and secondary school teachers is carrying out research in traditional ideas. In the beginning of BTTSC, the scientific education research method lecture is as the first lesson of BTTSC, and combine to train writing research papers and to publish production throughout the training process. The a series of methods are not only to meet the demands of subsequent graduation thesis guidance, but also to lay a good foundation for the trainees in school-based topic research after they back to their schools. 


\section{B. The science curriculum teaching methods were put into in the process of BTTSC to strengthen vocational skill of the trainees.}

1) Actual case analysis method (ACAM): ACAM can help teachers to improve their own education experience and examine and reflect on the level of theoretical analysis. In training, especially in education psychology, class management, science class teaching design, science textbooks analysis course, the trainers pay attention to select success or failure of the typical case in the educational reform, guide the trainees to self reflection from the analysis real education behavior, improve the ability to find the problem and solve the problem, cultivate BTSC are good at deepening the understanding of the work from existed problems through reflection, and improve the ability to solve problems and promote development.

2) Interactive activities: Interactive activities have been advocated the way of teaching especially in teaching reform of science course. Interactive activities changed that the teachers are the main bodies in teaching, and many production problems have been shown, too. Because the discussion is a teaching key skill of comprehensive science, In BTTSC, more interactive activities content has been arranged especially in the lectures of the text editor, the view in teaching and talking class, in BBS of the basic teaching level, and in science and technology innovation activity lecture, etc. The views and suggestions have exchanged, inspiration and consensus has been found by equal exchange and dialogue between trainers and trainees. The trainees have been improved in understanding and ability for their work in the teaching process of science course.

3) Visit and Investigation: BTSC will accelerate the teaching development of science course in the future. It is very important to deepen the understanding of the problems of teaching and find solution methods by opening field of vision. The trainees have been arranged to inspect and learn from teaching the lessons of science demonstration at Shijiazhuang city, to visit the school laboratory, to investigate the provincial science and technology museum, to visit the key laboratory of the university and the specimen rooms for the reason. The content of living examples also aroused attention to a few focus problems in science education, resulted in thinking related the education problems, and made trainees a more profound understanding in the nature of science, the mission of science and education work, and the direction of the curriculum reform,.

4) Inquiry teaching with science method: Inquiry teaching with science method is a central part of study. In training, we focused on practice content such as inquiry teaching content with science method, the STS course, experiment, and astronomical observation. We strengthened to guide trainees understanding and practice with the general process and method of scientific inquiry in training. The trainees have been also increased to obtain cognition of the teaching content by inquiry method in other training courses section. We potentially affect ability of science education to the trainees by strengthening to deepen the basic method of psychological process.

\section{Establish The Perfect Training Management MECHANISM By A Full RANGE OF SERVICE FunCTION}

The leading group of BTTSC have established by principal, administrative vice director and vice president of the teaching. It is responsible for the training of the overall arrangement and coordinating the various functional departments. The daily training agency was built by subject specialists, class specialty advisers and life advisers. It is responsible to make the training plan, arrange courses, supervise and inspect training process, organize visit and activities, etc. The training agency contact positively college computer room, library, network manage office, to provide sufficient manpower and material resources during the training.

The regular seminars about study and life have been conducted to find the problems and the needs of trainees in training. The general characteristic problems have been adjusted timely. All this is in order to adapt to meet the requirement of the dynamic function and training development in BTTSC. The trainees feel the college professional deep culture and humanistic care in the management in training. We also further promote the trainees thought, their reflections on its own scientific education work and training long-range plan of science education work, and symbiosis of action research and development of the school between trainers and trainees.

\section{ACKNOWLEDGMENT}

This work was supported by the educational science planning project for "the 11th five-year plan" in HeBei province (No.06020578).

\section{REFERENCES}

[1] W. Li, "Innovation enlightenment for teachers training model with action research method", Journal of vocational and technical education in China, vol. 196, pp. 42-44, 2005

[2] Y.L. Cha, "Discussion of constructing education mode", Journal of education research, vol. 6, pp. 34-36, 1997

[3] Z.G, Yuan, Education research methods, Beijing: Higher Education Publishing Company, 2000 .

[4] X.M. Chen. Qualitative research methods and social science research, Science Education Publishing Company, 2003

[5] L.L. Liu, Mode research about continuing education training for primary and secondary school teachers, Beijing, China Personnel Publishing Company, 2003 